\title{
Reconstruction and actual trends of landslide activities in Bruust-Haltiwald, Horw, canton of Lucerne, Switzerland
}

\author{
Philippe Burkhalter ${ }^{1,2}$, Markus Egli ${ }^{2}$, and Holger Gärtner ${ }^{1}$ \\ ${ }^{1}$ Swiss Federal Research Institute WSL, Birmensdorf, 8903, Switzerland \\ ${ }^{2}$ Department of Geography, University of Zürich, Zurich, 8057, Switzerland \\ Correspondence: Holger Gärtner (holger.gaertner@wsl.ch)
}

Received: 20 July 2018 - Revised: 6 March 2019 - Accepted: 8 March 2019 - Published: 22 March 2019

\begin{abstract}
A spatiotemporal reconstruction of slope movements on the edge of Lake Lucerne near the municipality of Horw, canton of Lucerne, is presented. The reconstruction was realized by analyzing growth reactions of beech (Fagus sylvatica L.) and fir (Abies alba Mill.) trees growing on this slope. Before dendrochronological sampling, a detailed geomorphological mapping of the landslide was conducted with the aim to determine the spatial extent of the sliding area. For tree-ring analyses, 124 increment cores from 62 trees were analyzed following standard techniques of dendrogeomorphology. In addition, long micro-sections were prepared from the entire cores to extend the common eccentricity analyses by microscopic determination of the onset of reaction wood in fir and beech. Results clearly show that the area is moving at least since 1948. A significant concentration of events was observed between the years 1990 and 2000 as well as after 2006. The definition of a threshold to define events using an eccentricity index alone is problematic and needs to be adapted to specific site conditions. For this reason, we recommend always combining the application of an eccentricity index with a detailed visual (anatomical) inspection to check for the occurrence of reaction wood.
\end{abstract}

\section{Introduction}

In Switzerland, around 6\%-8\% of the entire territory is endangered by mass movements (Lateltin, 1997). Although the pre-alpine and alpine areas are most likely to be affected (Lateltin, 1997), landslides occur especially frequently on slopes in the lowlands.

Geomorphologic events have been specified more frequently as potential consequences of increasing greenhouse gas emissions and climate change (Stock, 2005). According to Stoffel et al. (2014), precipitation values are expected to decrease during the summer, while they are expected to increase during spring and autumn. Extreme events that potentially threaten human life and infrastructure are showing an increasing trend (IPCC, 2014; Hufschmidt et al., 2005). Looking back in history, archival data provide information on past hazardous events (Röthlisberger, 1991), although these are mostly focusing on events causing severe damage to human life and infrastructure. Among these are the severe flooding in August 1987, causing damages of approx. CHF 800 million (Lateltin, 1997) or the most recent event, the Pizzo Cengalo rock avalanche (canton of Grisons) on 23 August 2017, causing subsequent mudflows that cost the lives of eight people and devastated the surroundings of the village Bondo. Despite these media-effective extreme events, there are numerous areas endangered by continuously moving landslides on a smaller scale, whereas their detailed extent or movement rate is still unknown. For the last decades, data on causing factors and process details are available in various archives, but further back in time archives rarely provided sufficient information on causing factors or magnitudes.

Rock avalanches and landslides do not depend on climate factors only. Despite triggering events, such as high precipitation, earthquakes, melting permafrost, or glacial activities, predispositional factors such as slope characteristics (slope angle, aspect, length, form), drainage density, distance from faults, lithology or land use determine the timing, frequency 


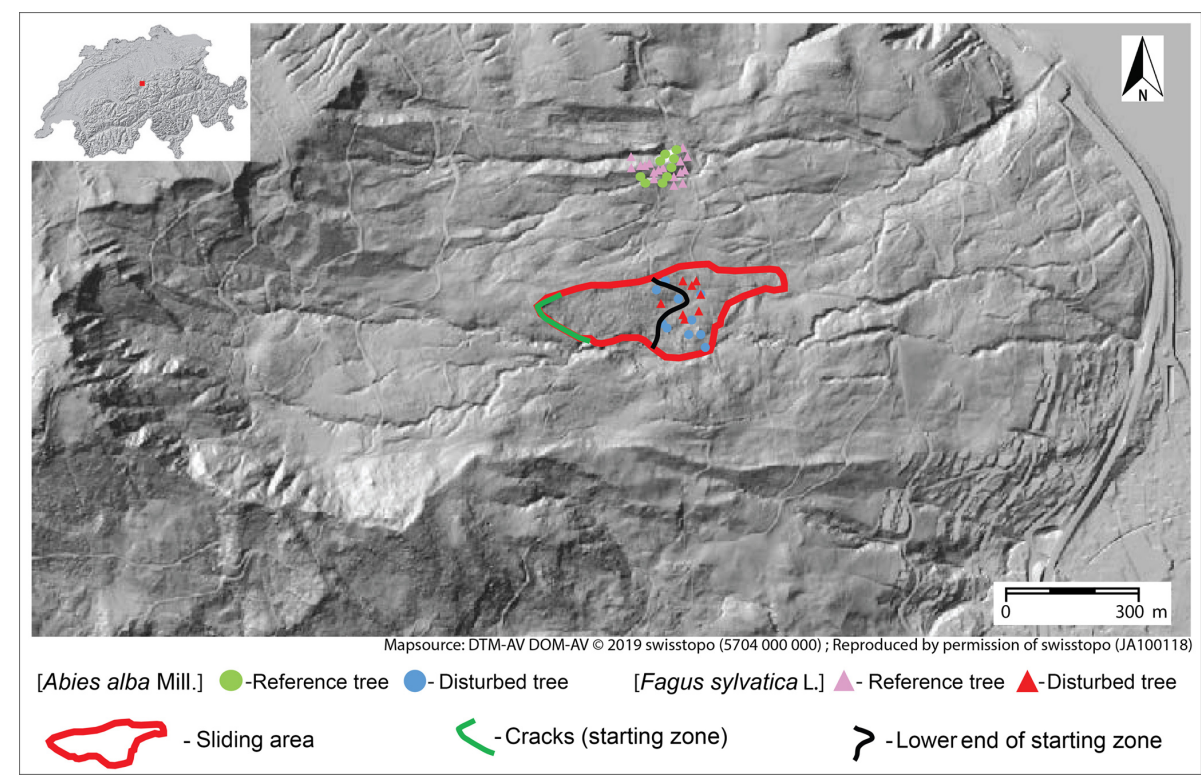

Figure 1. Outline map of the study area Bruust-Haltiwald, indicating the position of the trees sampled for the analyses presented (source: hillshade SwissALTI3D, national map LK25, (Swisstopo, 2019).

and dimension of such events (Reichenbach et al., 2018; Pourghasemi and Rahmati, 2017).

The conscious perception of hazards is necessary to overcome these challenges in a safe and responsible manner (Lateltin, 1997). In order to enable predictions about the future development of a risk, the activity of an area must be known, which can be deduced from reconstructing past events (Goudie, 1995). The focus should be set on areas where a risk exists and on the way it could affect humans and the environment. To determine the activity of geomorphic processes, observations, mapping, measurements and modeling are necessary. Although the density of measurement series tends to increase, measurements are commonly available at specific points only and, if so, over a relatively short period of time (Evans and Kirkby, 2004). This is exactly where the strength of dendrogeomorphology comes into play - the ability to date and reconstruct geomorphological events over a certain period of time depending on the maximum age of trees to be analyzed (Alestalo, 1971; Gärtner et al., 2004). The data obtained by dendrogeomorphological reconstructions can be included in a risk assessment and considered for the mandatory compilation of hazard maps for each municipality. As a last step, the implementation is realized by planning measures in the areas of spatial planning, protective measures and emergency planning (Lateltin, 1997). The detailed analysis of the severe weather conditions of 2005 and 2007 have shown that spatial planning measures are of great importance, especially because in these years slopes previously never recorded as potentially dangerous became unstable (BAFU, 2014). The aim of the study is to reconstruct the landslide activity of the Bruust-Haltiwald, a slope near the municipality of Horw, canton of Lucerne, by analyzing growth disturbances of beech (Fagus sylvatica L.) and fir (Abies alba Mill.) growing on this slope. This landslide is located just above the busy motorway $\mathrm{N} 2$, on the edge of the lake Lucerne. This motorway and the adjacent construction zone could be damaged if the landslide expands from its current position to the lower part of the slope.

\section{Study area}

The village Horw is located on the slope of Mt. Pilatus in the canton of Lucerne at an average altitude of $440 \mathrm{~m}$ a.s.l. The study area Bruust-Haltiwald (meaning "crack" - "heap, rubble") is located on the western flank of Mt. Pilatus (ca. 670$800 \mathrm{~m}$ a.s.l.) (Fig. 1). The area is covered with a millet grass beech forest (Milio-Fagetum typicum). The forest cover of the site is dominated by beech trees intermixed with fir and a very dense, species-rich understory. Between the rupture at the upper end and the lower boundary of the study area, the slope gradient is $31 \%\left(17^{\circ}\right)$ on average. Adjacent to the study area there are scattered residential and agricultural buildings, water and sewage pipes, the road Schwendelbergstrasse and several small forest roads or hiking trails. Power and telephone cables run directly through the area. Important traffic routes and a residential and construction zone belonging to the municipality of Hergiswil are located at the base of the slope (Louis, 1999).

Mt. Pilatus is located on the geological edge of the Alps and extends across Lake Lucerne (Vierwaldstättersee). It is composed of thick limestone rocks of the Cretaceous period (Schrattenkalk Formation) and Tertiary rocks (flysch) (Louis, 
1999). To the north, Mt. Pilatus lies on the subalpine flysch, which previously crossed the subalpine molasses. Together with the Bürgenstock and Rigi, Mt. Pilatus is part of the Helvetic border chain and defines the front of the sediment series Drusberg. These series are part of the Helvetic nappe system. The study area Bruust-Haltiwald is located $2 \mathrm{~km}$ north of the main Alpine thrust fault.

The bedrock of the study area is composed of more than $1000 \mathrm{~m}$ of marl, sandstone and molasses conglomerate deposits of the lower freshwater molasses (Louis, 1999). The layers are inclined by $30-45^{\circ}$ towards SSW in normal bedding. Marl and sandstone dominate the lower part, while calcareous sandstone and banks of molasses dominate at higher altitudes (Louis, 1999). The almost impermeable clay and unconsolidated rocks rich in silt give rise to the large meteoric water surface runoff. The slope water moves in randomly distributed cracks and layer boundaries. The natural discharge of springs strongly swamps the environment since the drainage only captures small catchment areas. This mainly affects flatter slopes and depressions (Louis, 1999).

The area is characterized by a seasonal climate: annual precipitation in the Mt. Pilatus summit region is about $1800 \mathrm{~mm}$ and in the range of the study site at $1250 \mathrm{~mm}$, with an annual average temperature of $9.4^{\circ} \mathrm{C}$. Highest precipitation values are reached in the period January to April (monthly average: $200 \mathrm{~mm}$ ). According to Blanke and Herzog (2012) an average annual increase in precipitation of about $1 \%$ is expected for the period December to April. Consequently, a higher amount of water penetrating the soil will increase the risk of landslides in the area.

\section{Methods}

\subsection{Sampling strategy}

The study area was checked for potential slope movement indicators using a digital elevation model (hillshade SwissALTI3D 1: 10 000; Swisstopo). Within this model, areas characterized by rough, uneven surfaces were identified, indicating surface movements. In the field, these specific areas were then checked for cracks, ridges and tilted trees, indicating terrain movement. A Garmin eTrex Vista was used to measure fixed points in the terrain, for example allowing point measurements of tree positions within the study site with an accuracy of $\pm 2 \mathrm{~m}$. These points were subsequently processed in ArcGIS 10.5.1 (ESRI Inc.). Distances, elevations and inclinations of trees were measured using the Vertix IV GS from Haglof. The resolution of the distance of this device is $\pm 0.01 \mathrm{~cm}$.

Fir (Abies alba Mill.) and beech (Fagus sylvatica L.) were selected for the analyses, because the two tree species are dominant in the entire landslide and surrounding areas. The selection of trees to be sampled for tree-ring analyses was based on the following criteria:
- visible influence from landslide activities (e.g., tilted stems, skew or saber growth);

- no impact on the stem by rockfall.

Due to the difficult accessibility of the upper part of the landslide and a lack of obviously affected trees, almost only trees on the lower part of the landslide were chosen (see black line in Fig. 1). Trees were sampled over the entire width of the landslide to detect any potentially existing movement characteristics.

Increment cores with a diameter of $5 \mathrm{~mm}$ were taken from the trees using a Swedish corer (Mora-Coratex by Haglöfs). The sampling was performed according to given standards, as described in Gärtner et al. (2004). At least two opposing core samples were taken from each tree (Cook and Kairiukstis, 1990). The sampling was always done in parallel to the direction of the stem inclination, with one core on the top side of the stem and one on the lower side of the tilted stem. In total, 11 trees (44 cores) were sampled per species on the landslide.

A stable, undisturbed site in the close vicinity of the landslide was selected to create a reference chronology, representing the "common growth" of the two tree species in this area. For this, trees without any visual sign of disturbance were selected. Because the reference site was also located on a slope, two opposing cores were taken parallel to the slope to exclude possible disturbances and growth anomalies caused by potentially undetected slope movements (Gärtner et al., 2004). The number of trees necessary for a reference chronology varies widely in literature. According to Schweingruber (1996), the standard set comprises at least 15 trees. For the reference chronologies of this study, 20 trees were sampled per species, resulting in a total of 80 increment cores.

\subsection{Dendrochronological analyses}

All samples were treated following given standards of dendrochronology including ring-width measurement and subsequent cross-dating (Cook and Kairiukstis, 1990; Stoffel and Bollschweiler, 2008). The cores were glued on wooden mounts and cut with a core microtome to create plane surfaces for ring-width measurement (Gärtner and Nievergelt, 2010). Tree-ring measurement was done using the semiautomatic measuring table, Lintab (Frank Rinn, Heidelberg, Germany), combined with a stereomicroscope (Leica Wild M8; 6x-50x) and the Time Series Analysis Program, TSAP (Rinn, 2003), with a precision of $0.01 \mathrm{~mm}$. The reference chronology was compiled in the same way and serves as the basis for cross-dating of the samples taken on the landslide area. Missing tree rings were detected and corrected manually.

Subsequently, eccentric growth was visually detected based on ring-width measurements. Based on the intensity of the difference between the two opposing ring-width measurements, events were marked as possible, probable and certain 


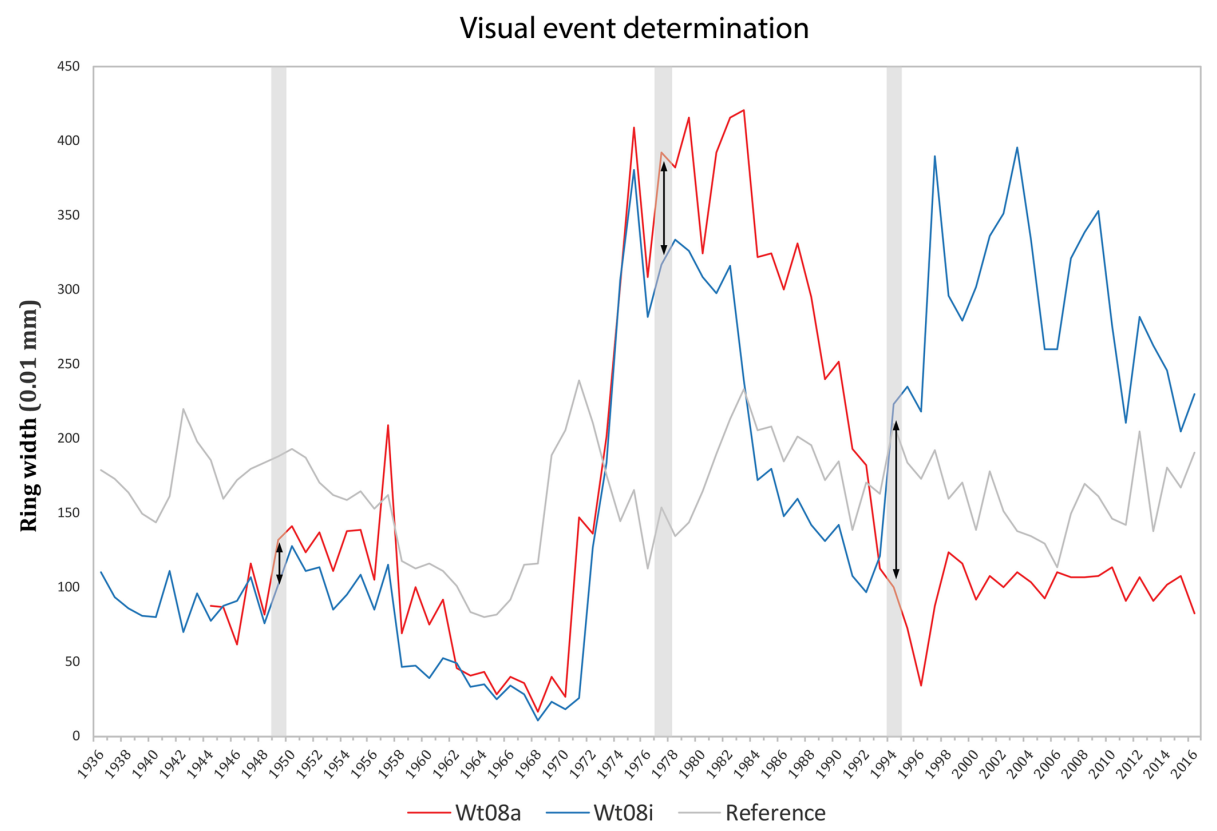

Figure 2. Response age dating based on the eccentricity of the curves. Depending on the intensity of divergence of the upper (Wt08a) and lower (Wt08i) stem sides events can be defined as possible, probable or certain before further analyses are conducted.

(Fig. 2). The final determination of these markings as events was confirmed by visually determining the occurrence of reaction wood, namely compression wood in conifers (macroscopic; on the surface of the cores) and tension wood in hardwoods, as beech (microscopic; inspection of micro-sections). The occurrence of reaction wood in response to a tilting of the stem (Gers et al., 2001; Malik and Wistuba, 2012) is one of the most important signs of past sliding events. The macroscopically visible color of compression wood ranges from yellow-red to brown-red. Compression wood cells, characterized as thick walled, round cells showing intercellular spaces (Timell, 1986a, b) can be analyzed on the cut, plane surface of the cores under a binocular at $40 \mathrm{x}$ magnification.

In contrast to compression wood, tension wood in hardwoods is not visible macroscopically. As a consequence, micro-sections of the entire increment cores (Gärtner et al., 2015) from beech were prepared for further analyses under a microscope. Tension wood from beech is characterized by a gelatinous fiber attached to the inner part of the fiber cell walls, which is only visible when adding specific stains to the micro-sections. For this reason, all thin sections were stained with safranin, the lignin of the cell walls was stained red and astra blue, nonlignified parts were stained - as gelatinous fibers - blue (Gärtner and Schweingruber, 2013; Bräuning et al., 2016).

\subsection{Eccentricity index}

To potentially control the results of the visual reaction analysis, the eccentricity index of Wistuba et al. (2013) was applied. The index was tested for a large area of slips. By sub- tracting the tree-ring width $\left(D_{x}\right)$ of the lower side from the upper side of the inclined stem $\left(U_{x}\right)$, the simple eccentricity $E_{x}$ is calculated following Eq. (1):

$E_{x}[\mathrm{~mm}]=U_{x}-D_{x}$.

This results in the calculation of the eccentricity index $\mathrm{Ei}_{x}$. The sign defines the process direction and the index is calculated as a percentage of the thinner tree ring. As a result, the slope movement can be reconstructed.

$$
\begin{aligned}
& \text { if } E_{x}[\mathrm{~mm}]>0 ; \mathrm{Ei}_{x}[\%]=\left(E_{x} / D_{x}\right) 100 \% \\
& \text { if } E_{x}[\mathrm{~mm}]=0 ; \mathrm{Ei}_{x}[\%]=E_{x}[\mathrm{~mm}]=0 \\
& \text { if } E_{x}[\mathrm{~mm}]<0 ; \mathrm{Ei}_{x}[\%]=\left(E_{x} / U_{x}\right) 100 \%
\end{aligned}
$$

The actual dating of an event is detected by calculating the eccentricity index in comparison to the previous year $v \mathrm{Ei}_{x}$ following Eq. (5):

$v \mathrm{Ei}_{x}[\%]=\mathrm{Ei}_{x}-\mathrm{Ei}_{x}-1$.

Expressing the index in percentage rather than millimeters gives the opportunity to compare trees of different species and research areas (Wistuba et al., 2013). The threshold value is finally calculated using the reference measurement series. Composed of the arithmetic mean and the standard deviation, it defines a value for the positive $v \mathrm{Ei}_{x}$ and the negative $v \mathrm{Ei}_{x}$. Years exceeding the specified limit are to be interpreted as event years. 


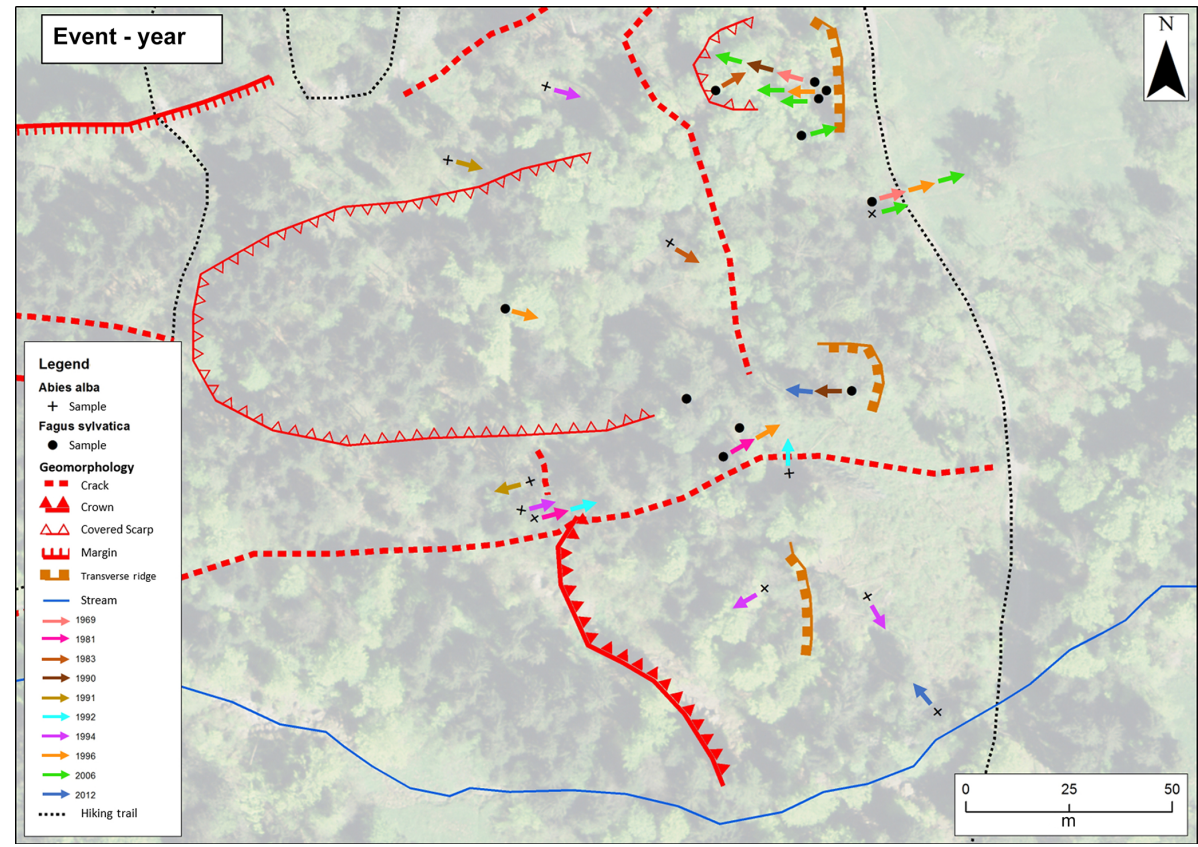

Figure 3. The chart of field mapping shows years in which an event was recorded in cores. Only those events observed in two or more cores are listed. According to the crack running east to west, the landslide can be divided into a northern and a southern part (source: Swissimage, (C) Swisstopo, 2017).

\section{Results}

\subsection{Eccentricity analyses}

The oldest ring dated in a tree of the site is dated to 1929 (fir Wt08). Within the rings of the analyzed 22 trees, 43 events were dated based on determining the onset of ring-eccentricity in combination with the onset of reaction wood as a direct response to stem tilting. The oldest dendrochronological event was dated to 1949 (fir sample Wt08) and for beech to 1950 (sample Bu09i). A significant concentration of events can be observed between the years 1990 and 2000. Another increase in the number of events was identified in 2006. The eccentricity index clearly revealed more events than a visual analysis.

Within the conifers, a maximum of three reactions per tree (fir Wt06) were detected. Each of the fir samples Wt02, Wt03, Wt04, Wt05 and Wt10 only show one event identified in the cores. Two events were dated in each of the cores Wt01, Wt07, Wt08, Wt09 and Wt11. The years 1991, 1992 and 1994 had the highest number of trees showing detectable responses. In 1991 and 1992, a reaction was found in two trees, while an event in 1994 was dated in four trees. In total, 18 reactions classified as certain were identified in the 11 trees examined.

One to five reactions per year were detected and labeled among the beech samples. The sample Bu07 shows only one reaction triggered by an event (1993), while two events are determined by the trees Bu03 (1996, 2006) Bu04 (1998,
2006), Bu05 (1983, 2005), Bu06 (1982, 1996), Bu08 (1981, 1996) and Bu09 (1950, 2002). Three events were recorded by the cores from the beeches Bu01 $(1987,2000,2006)$, Bu02 (1969, 1990, 2006), Bu10 (1970, 1990, 2012) and B11 $(1969,1996,2006)$. The analysis shows that the event years 1996 and 2006 are detectable in more trees than in other years (reactions in four or five cores).

It has to be noted that four events dated to $2007 \mathrm{had}$ to be corrected after the wood anatomical analysis due to an earlier onset of tension wood than the first occurrence of eccentricity. Also, in the visual event dating, beeches show more frequent reactions than firs. In total, 25 events were found in 11 samples.

To date the clear event years, all years with at least two trees showing a response were highlighted. The resulting map shows the location of fir trees (crosses) and beeches (dots) on the landslide (Fig. 3). The colored arrows indicate in which year a reaction was dated and, furthermore, the direction of the disturbance. As a result, in 1969, 1981, 1983, 1990, 1991, 1992 and 2012, a response was found in two trees. In 1994, 1996 and 2006 reaction wood was dated in four or six trees.

\subsection{Eccentricity index}

The calculation of the eccentricity index was applied to all tested trees. The index shows the percentage change in relative values compared to the previous year. The related calculation of the threshold from control trees for Abies alba 


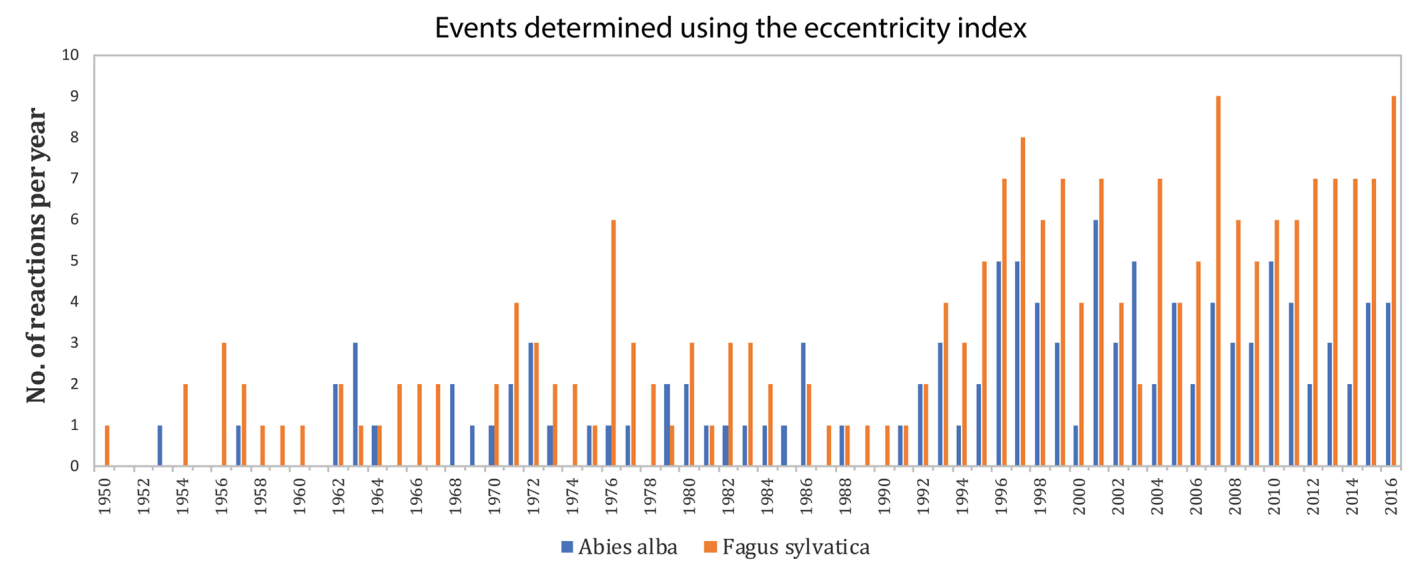

Figure 4. Comparison of the results of Abies alba and Fagus sylvatica using the eccentricity index. The diagram shows an accumulation of events around 1972 and from 1992 onwards.

yielded $-73.02 \%$ on the lower side and $48.29 \%$ on the upper side of the trees. Since Fagus sylvatica does not form compression wood but tension wood, the signs had to be reversed. The threshold of the lower side of the tree stem is at $34.53 \%$, while the threshold on the upper side is $-43.11 \%$. If $v \mathrm{Ei}_{x}$ exceeds the previously calculated threshold value, then a tilting has occurred in the corresponding year.

Per Abies alba tree, on average 10 reactions were dated using the eccentricity index (Fig. 4). The values of sample Wt04 did not reach the calculated thresholds; therefore no reaction could be detected for this tree. Compared to the previous year, only minor changes occurred, resulting in low $v \mathrm{Ei}_{x}$ values. The calculated eccentricity index values of the trees $\mathrm{Wt} 01, \mathrm{Wt} 05$ and $\mathrm{Wt} 07$ were below average of the thresholds, whereas the values of the trees $\mathrm{Wt} 02$, Wt03, $\mathrm{Wt} 08, \mathrm{Wt}, 09$, Wt10 and Wt11 were above average.

The dated events per year of Abies alba tend to increase over time and show the highest responses in 1996, 1997, 2001, 2003 and 2010. Related years have been distinguished with the reaction dating between 1994 and 1997. Thus an increase in the number of events since 1990 is apparent.

An average of 19 events per Fagus sylvatica tree were dated using the eccentricity index (Fig. 4). The samples Bu01, Bu04, Bu05, Bu06 and Bu07 are below the calculated average, whereas the samples Bu02, Bu08, Bu09 and $\mathrm{Bu} 10$ are above the arithmetic mean of the thresholds. Sample $\mathrm{Bu} 03$ shows 19 reactions and thus reflects the mean of all reactions found. An increase in events can be seen from 1990 onwards with an accumulation 1996, 1997, 1998, 1999, 2001, 2004 and 2007.

When comparing the two tree species, Fagus sylvatica samples demonstrate a higher number of reactions. This is due to an increased number of reactions among Fagus sylvatica in 1976. After 1995 an increase in the reactions for both species has been taken place.

When comparing the results of visual response dating of Fagus sylvatica with the eccentricity index, then the latter procedure dates significantly more events (Fig. 5). While response dating based on a visual determination of the onset of eccentricity revealed a maximum of three events per tree, the index-based results showed 10 to 30 events over the same time period. However, both methods show an increase in registered events per year in 1996 and 2006. Interestingly, in 1969, visual response dating shows tension wood in two cores, while the eccentricity index did not detect any event. Thus, 1969 is the only year in which visual reaction dating identified an event that could not be captured by the eccentricity index. The year 1990 is noteworthy, because reaction wood was found in the visual reaction dating in two trees, whereas the eccentricity index produced a result in one tree only. In all other cases, the number of events dated using the eccentricity index exceed those detected by visual response dating.

Comparing the results between the visual response dating and the eccentricity index of Abies alba demonstrates a similar pattern (Fig. 6). At most, three events per tree were dated using visual response dating. The eccentricity index registered a maximum of 19 reactions and at least two events per tree. Fir Wt04 is an exception, as the eccentricity index recorded no event at all. Visual response dating detected an event in four trees in 1994. The same increase in number was not recognizable with the eccentricity index, which recorded only one reaction. Also in 1991, visual reaction dating revealed an event in two cores, while the eccentricity index detected only one reaction. In 1955 and 1960, the eccentricity index was unable to detect any reactions. However, visual reaction dating found compression wood in one core each.

\section{Discussion}

Based on the results obtained, reaction wood was found in all examined trees. Hence, the study area is certainly affected by slope movements. However, a clear pattern of movement and thus a division of the study area into different landslide sec- 

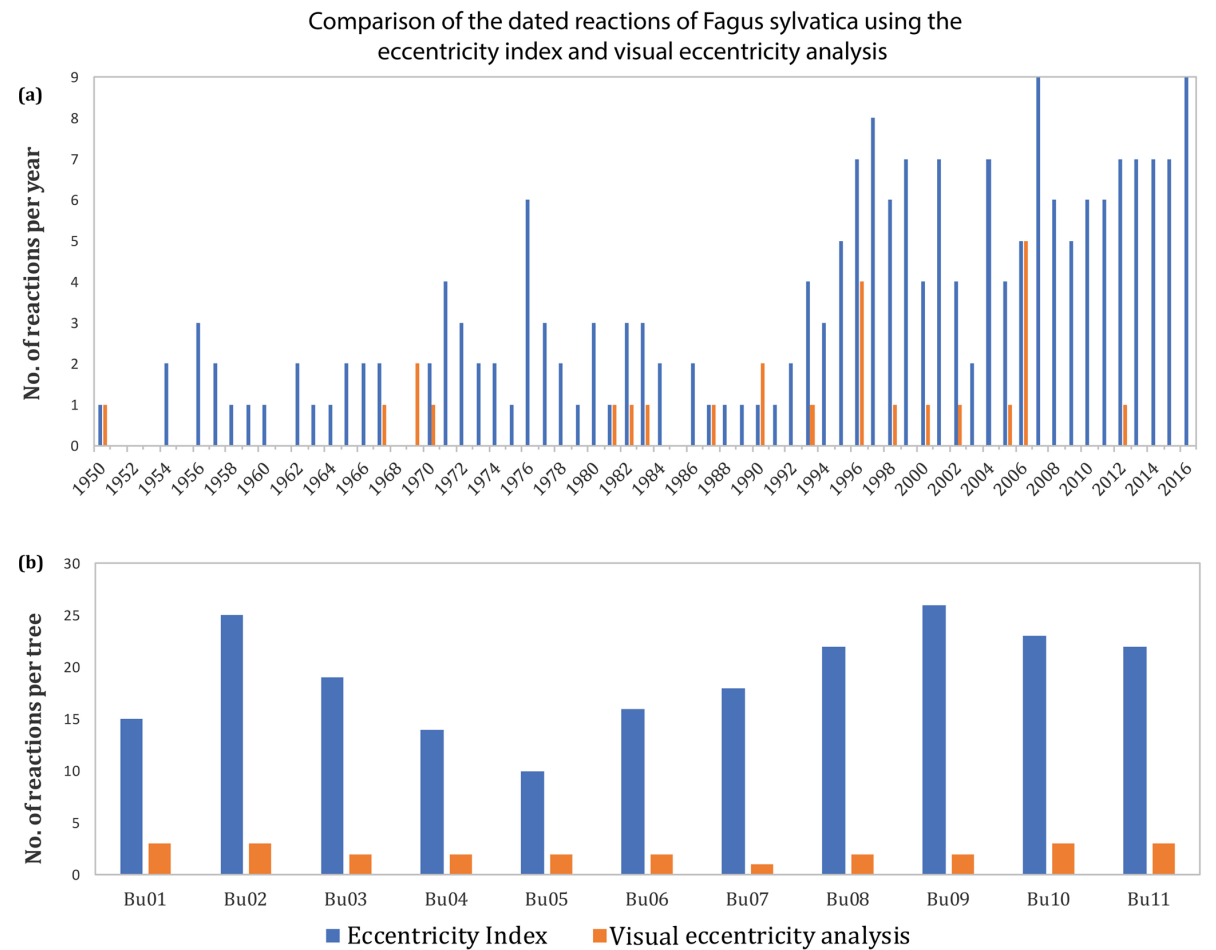

Figure 5. Comparison of the dated responses of Fagus sylvatica using the eccentricity index and the reaction dating. The comparison of reactions (a) per year and (b) per tree.
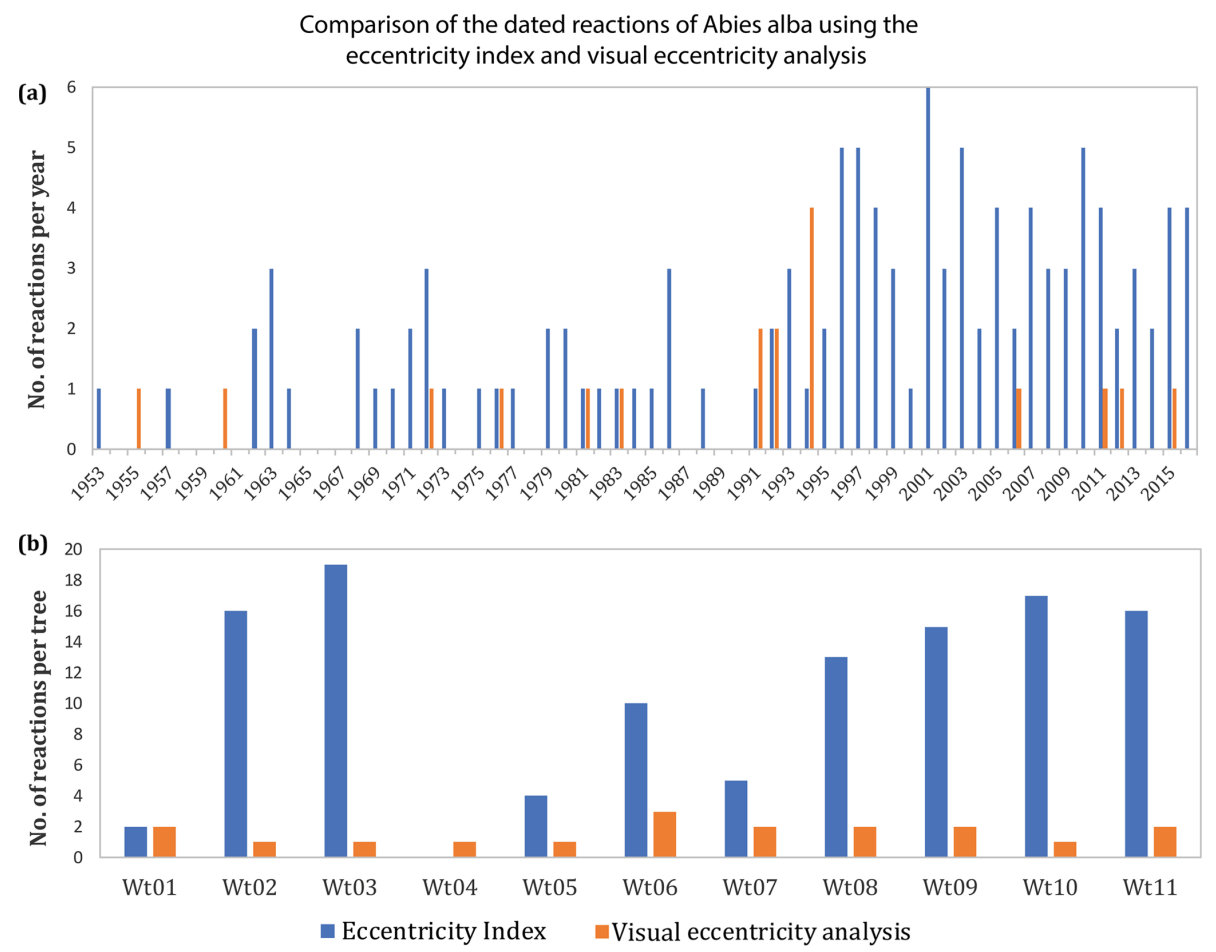

Figure 6. Comparison of the dated responses of Abies alba using the eccentricity index and the reaction dating. The comparison of reactions (a) per year and (b) per tree. 
tors could not be achieved. The age of the landslide activities could not be determined. They seem to be much older than the first dated response in 1950 . The dating of single events is, however, very accurate thanks to the wood anatomical examination.

\subsection{Eccentricity analyses}

The dendrogeomorphic analysis of 44 cores taken from 22 trees allowed 43 events to be dated. The temporal resolution could be determined exactly; however only assumptions can be made about the spatial resolution, since the movement mostly occurred on single spots only. The movements are often not coherent, but seem to occur in two lanes. The fir and beech trees react to events regardless of their location. A division into a northern and southern part of the landslide could be made (Fig. 3), since the movements were most frequently recorded in the northern part of the landslide. However, a movement pattern within these two zones was not recognized. Movements of the southern part of the slide seem to be triggered by the strong tear-off edge directly above fir Wt08. Whether movements of the northern and southern parts are connected or not (i.e., if the movement of the northern part caused the movement of the southern part) could not be determined. The only event that could be clearly delineated spatially is of the one in 2006, which was recorded in six trees. Due to the anticlinal tilting of the trees and the bulge below, a rotational movement of the ground appears to be certain. Nevertheless, dividing the area into zones based on the visually detectable type of movements is not applicable. For this the analysis was carried out according to years of events. Generally speaking, between 1990 and 2010, an accumulation of movements from the upper to the lower part of the slope was propagated. While movements took place mainly in the middle of the slope from 1990 to 1999 , more activities occurred on the slope foot between 2000 and 2009.

One possible explanation for the missing pattern is provided by Shroder (1980) and Carrara and O'Neill (2003), who stated that reactions to an event may occur one or even several years later in tree rings. Also, the size of the data set of 22 individuals is at the lower end of suggested quantities. According to Corona et al. (2014), records with up to 50 individuals are considered small and data sets around 100 individuals are considered as optimal. But these recommendations are applicable for large study areas only, where sampling of 50 to 100 potentially disturbed trees is possible. According to Denneler and Schweingruber (1993), it is easier to date nonrecurring, distinct events than less obvious, recurring events. Therefore, it can be assumed that not all reactions of the defined investigation area could be discovered and dated.

Another source of error lies in the analysis of thin sections. In four of the seven samples, the dating had to be adjusted, since compression wood was already found in the latewood of the previous year. Šilhán and Stoffel (2015) described an "error rate" when comparing eccentricity and the macroscopic analysis of prepared thin sections. It turned out to be a significant problem in the exact dating of years. To ensure the accuracy in the year-specific dating of events, it is therefore essential to combine eccentricity analyses with the analyses of thin sections as done in this study.

The basis for this is in the core microtome, which allows for thin sections over the entire core and thus over a long time series. According to Heinrich and Gärtner (2008), this is an applicable tool for supporting or even improving the dating with additional information.

\subsection{Eccentricity index}

Although the same data were used for the eccentricity index and for the reaction dating, the results are not always consistent (Fig. 7). Some of the reactions detected by the index might be overcompensation of single trees to a strong disturbance or simply a result of tree recovery as mentioned by Wistuba et al. (2013) (see crosses in Fig. 7). Nevertheless, setting a definite threshold seems to be a critical point when using the index, as it is the case for all other existing indices. Using the reference trees to define a site-specific common eccentricity is a good indicator, but the definite level needs to be adjusted to the sensitivity of the disturbed trees. For this reason, no quantitative confirmation of the results could be achieved based on the eccentricity index alone.

When comparing the eccentricity index with visual reaction dating, it is noticeable that event years classified as certain using visual reaction dating are far from reaching the threshold set for the eccentricity index. For example, sample Wt09 classified the years 1960 and 1994 as certain. However, the signal interpreted by the index in 1960 with the value $v \mathrm{Ei}_{x}=3.01 \%$ does not reach the threshold of $48.29 \%$. The same pattern can be seen in 1994, where $v \mathrm{Ei}_{x}=-20.7 \%$, while the threshold is set at $-73.02 \%$. It is obvious that the index does not take subsequent years into account. The interpretation of the index, which allows subsequent years to exceed the threshold value after an initial event and thus be defined as trigger years, is not considered to be applicable without further detailed inspection of the reaction wood. Therefore, it can be assumed that calculated thresholds do represent an important base for an objective event determination, but they are not suitable as a standalone procedure for a study area showing intense disturbances. Although the assumptions of Wistuba et al. (2013) are given for an application of the index it could not complement, let alone replace, the visual (anatomical) reaction dating.

Since the values of $v \mathrm{Ei}_{x}$ are frequently very close to the thresholds, adjusting the thresholds would also not achieve the desired effect. Years of visual reaction dating do rarely agree with an index-based year, suggesting that the eccentricity index of Wistuba et al. (2013) cannot be applied alone in the investigated area. According to Wistuba et al. (2013), the index is applicable in areas affected by a single process only. 

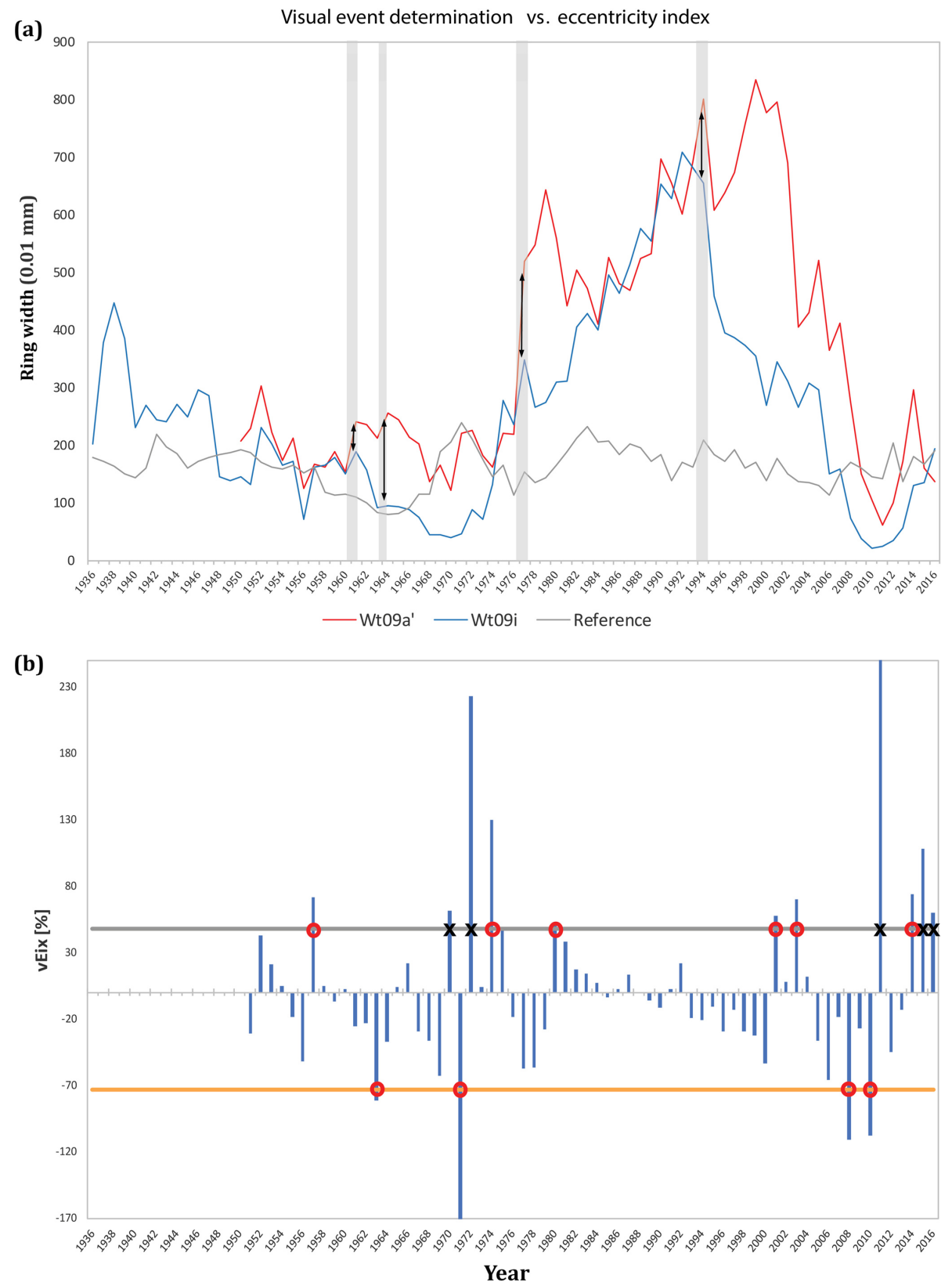

Figure 7. Dated responses from reaction dating (a) and the eccentricity index (b). Gray bars mark event years dated from visual reaction dating (1960, increase in 1964, 1977 and 1994). These years were not recognized as event years by the eccentricity index. The red circles show the seemingly most obvious events. X represents values exceeding the threshold as a result of potential tree recovery or as an ongoing effect of a disturbance before. So they cannot be defined as events without doubt.

In a geomorphologically active area, where ground movements may occur multiple times, it is conceivable that a second event might occur, while trees still compensate for the skewness of a first event. Such a reaction will only be recognizable by the divergence in the growth curve and the visual analysis of the core but not by a new increase in the eccentricity value $v \mathrm{Ei}_{x}$. It should also be kept in mind that the increase in $v \mathrm{Ei}_{x}$ due to sudden eccentricity may detect an event, but the index is unable to determine the exact timing of an event without determining changes in the anatomical structure. If an event occurs towards the end of the growing season, the index will not be able to detect it. Although the last part of the ring might show reaction wood as a clear sign of a disturbance, the eccentric growth will not be apparent until the next year. This verification is easier with visual response dating and can be done directly under the microscope. For this reason, we recommend always combining the application of the eccentricity index following Wistuba et al. (2013) with 
a detailed visual (anatomical) inspection of the ring prior to the year determined by the index to check for the occurrence of reaction wood.

\section{Conclusion}

In total, 27 slide events were dated from 1950 to 2015. In order to increase the quality, thin sections of selected samples were prepared in addition to the eccentricity analysis, which resulted in the correction of some dated events. Since there are no historical data on landslide events from that area, no comparison could be made with known events. However, it has been clearly demonstrated that the area has had ground movements ever since the 1950s and that a decline in movement is not expected. An accurate and coherent resolution of these movements is extremely difficult because of many individual and unrelated events. Although a wood anatomical analysis is time consuming, it does provide important additional and detailed information.

The eccentricity index of Wistuba et al. (2013) did not yield the desired results when applied without additional anatomical inspections. It became obvious that visual reaction dating must be applied. The sensitivity of the trees in the study area showed that the definition of a site-specific threshold for the application of the index seems to be critical to adequately differentiate between common, potential eccentricity (e.g., wind induced) and a mechanically induced eccentricity owing to processes acting on the slope of interest. A review of the index is considered useful and necessary for additional research areas.

Limiting factors of this dendrogeomorphological reconstruction are the size of the data set and the age of sampled trees. The spatial limitation of sampled trees should also be reconsidered in a further analysis.

Data availability. For reasons of data protection, data used for this publication can be requested from the corresponding author.

Author contributions. PB conducted fieldwork as well as sample preparation and analyses. HG and ME supported him in defining the sampling strategy, doing the data analyses and writing the manuscript.

Competing interests. The authors declare that they have no conflict of interest.

Acknowledgements. The authors are grateful to two anonymous reviewers for their valuable comments on the manuscript.
Review statement. This paper was edited by Isabelle GärtnerRoer and reviewed by two anonymous referees.

\section{References}

Alestalo, J.: Dendrochronological interpretation of geomorphic processes, Fennia, 105, 1-140, 1971.

BAFU - Bundesamt für Umwelt: Schutz vor Massenbewegungsgefahren, Vollzugshilfe für das Gefahrenmanagement von Rutschungen, Steinschlag und Hangmuren, Umwelt-Vollzug, Bundesamt für Umwelt, Bern, 2014.

Blanke, V. and Herzog, F.: Klimawandel, Nutzungswandel und Alpwirtschaft, Schlussbericht des AlpFUTUR-Teilprojektes 4 "Klima", Teil 1, Forschungsanstalt Agroscope ReckenholzTänikon ART, Zürich, 59 pp., 2012.

Bräuning, A., De Ridder, M., Zafirov, N., García-González, I., Dimitrov, D. P., and Gärtner, H.: Tree-ring features: indicators of extreme event impacts, IAWA J., 37, 206-231, https://doi.org/10.1163/22941932-20160131, 2016.

Carrara, P. E. and O'Neill, J. M.: Tree-ring dated landslide movements and their relationship to seismic events in southwestern Montana, USA, Quaternary Res., 59, 25-35, https://doi.org/10.1016/S0033-5894(02)00010-8, 2003.

Cook, E. R. and Kairiukstis, L. A.: Methods of Dendrochronology: Applications in the Environmental Sciences, Kluwer, Dordrecht, Boston, London, 1990.

Corona, C., Lopez Saez, J., and Stoffel, M.: Defining optimal sample size, sampling design and thresholds for dendrogeomorphic landslide reconstruction, Quatern. Geochronol., 22, 72-84, https://doi.org/10.1016/j.quageo.2014.02.006, 2014.

Denneler, B. and Schweingruber, F. H.: Slow mass movement. A dendrogeomorphological study in Gams, Swiss Rhine Valley, Dendrochronologia, 11, 55-67, 1993.

Evans, D. J. A. and Kirkby, M.: Geomorphology: critical concepts in geography, in: Hillslope geomorphology, Vol. 2, Routledge, London, 2004.

Gärtner, H. and Nievergelt, D.: The core-microtome: A new tool for surface preparation on corse and time series analysis of varying cell parameters, Dendrochronologia, 28, 85-92, https://doi.org/10.1016/j.dendro.2009.09.002, 2010.

Gärtner, H. and Schweingruber, F. H.: Microscopic preparation techniques for plant stem analysis, Verlag Dr. Kessel, RemagenOberwinter, p. 78, 2013.

Gärtner, H., Esper, J., and Treydte, K.: Geomorphologie und Jahrringe. Feldmethoden in der Dendrogeomorphologie, Schweiz. Z. Forstwes., 55, 198-207, 2004.

Gärtner, H., Banzer, L., Schneider, L., Schweingruber, F. H., and Bast, A.: Preparing micro sections of entire (dry) conifer increment cores for wood anatomical time-series analyses, Dendrochronologia, 34, 19-23, https://doi.org/10.1016/j.dendro.2015.03.004, 2015.

Gers, E., Florin, N., Gärtner, H., Glade, T., Dikau, R., and Schweingruber, F. H.: Application of shrubs for dendrogeomorphological analysis to reconstruct spatial and temporal landslide movement patterns - A preliminary study, Z. Geomorphol. Supp., 125, 163$175,2001$.

Goudie, A. S.: The changing earth: rates of geomorphological processes, in: The natural environment, Blackwell Pub, Oxford, 1995. 
Heinrich, I. and Gärtner, H.: Rekonstruktion von Massenbewegungen mithilfe der Holzanatomie, Schweiz. Z. Forstwes., 159, 5865, https://doi.org/10.3188/szf.2008.0058, 2008.

Hufschmidt, G., Crozier, M., and Glade, T.: Evolution of natural risk: research framework and perspectives, Nat. Hazard. Earth Syst. Sci., 5, 375-387, https://doi.org/10.5194/nhess-5375-2005, 2005.

IPCC: Synthesis Report, in: Contribution of Working Groups I, II and III to the Fifth Assessment Report of the Intergovernmental Panel on Climate Change, edited by: Core Writing Team, Pachauri, R. K., and Meyer, L. A., IPCC, Geneva, Switzerland, 151 pp., 2014.

Lateltin, O.: Berücksichtigung der Massenbewegungsgefahren bei raumwirksamen Tätigkeiten, Technical Report, Bundesamt für Raumplanung BRP, Bundesamt für Wasser-wirtschafft BWW, Bundesamt für Umwelt, Wald und Landschaft BUWAL, Bern, 1997.

Louis, K.: Gefahren-/Risikoanalyse zur Sicherheitsplanung im Gefahrengebiet Bruust/Haltiwald der Gemeinden Horw/LU und Hergiswil/NW, Untersuchungsbericht mit 10 Beilagen, Gemeinde Horw, Horw, 1999.

Malik, I., and Wistuba, M.: Dendrochronological methods for reconstructing mass movements - An example of landslide activity analysis using tree-ring eccentricity, Geochronometria, 39, 180 196, https://doi.org/10.2478/s13386-012-0005-5, 2012.

Pourghasemi, H. R. and Rahmati, O.: Prediction of the landslide susceptibility: Which algorithm, which precision?, Catena, 162, 177-192, https://doi.org/10.1016/j.catena.2017.11.022, 2017.

Reichenbach, P., Rossi, M., Malamud, B. D., Mihir, M., and Guzzetti, F.: A review of statistically-based landslide susceptibility models, Earth Sci. Rev., 189, 60-91, https://doi.org/10.1016/j.earscirev.2018.03.001, 2018.

Rinn, F.: TSAP-Win. Time series analysis and presentation for dendrochronology and 409 related applications, User reference, Rinntech, Heidelberg, 2003.
Röthlisberger, G.: Chronik der Unwetterschäden in der Schweiz, Berichte der Eidgenössischen Forschungsanstalt für Wald, Schnee und Landschaft, Birmensdorf, 330 pp., 1991.

Schweingruber, F. H.: Tree rings and environment, Dendroecology, Paul Haupt, Bern, Stuttgart, Wien, 1996.

Shroder, J. F.: Dendrogeomorphology: review and techniques of tree-ring dating, Prog. Phys. Geogr., 4, 161-188, https://doi.org/10.1177/030913338000400202, 1980.

Šilhán, K. and Stoffel, M.: Impacts of age-dependent tree sensivity and dating approaches on dendrogeomorphic time series of landslides, Geomorphology, 236, 34-43, https://doi.org/10.1016/j.geomorph.2015.02.003, 2015.

Stock, M. (Ed.): KLARA - Klimawandel-Auswirkungen, Risiken, Anpassungen, PIK-Summary Report No. 99, Institut für Klimaforschung, Potsdam, 2005.

Stoffel, M. and Bollschweiler, M.: Tree-ring analysis in natural hazards research - an over-view, Nat. Hazards Earth Syst. Sci., 8, 187-202, https://doi.org/10.5194/nhess-8-187-2008, 2008.

Stoffel, M., Tiranti, D., and Huggel, C.: Climate change impacts on mass movements - Case studies from the European Alps, Sci. Total Environ., 493, 1255-1266, https://doi.org/10.1016/j.scitotenv.2014.02.102, 2014.

Swisstopo: Hillshade SwissALTI3D, national map LK25, () Swisstopo, SwissImage, Google Earth, 2017.

Swisstopo: Hillshade SwissALTI3D, national map LK25, (C)Swisstopo, Geländemodell, Google Earth, 2019.

Timell, T. E.: Compression Wood in Gymnosperms, Springer, Berlin, Heidelberg, New York, Tokyo, 1986a.

Timell, T. E.: Compression Wood in Gymnosperms 2, Springer, Berlin, Heidelberg, New York, Tokyo, 1986b.

Wistuba, M., Malik, I., Gärtner, H., Kojs, P., and Owczarek, P.: Application of eccentric growth of trees as a tool for landslide analyses: The example of Picea abies Karst, in the Carpathian and Sudeten Mountains (Central Europe), Catena, 111, 41-55, https://doi.org/10.1016/j.catena.2013.06.027, 2013. 